\title{
Identifying A Policymaker's Target: An Application to the Bank of Canada
}

\author{
Nicholas Rowe \\ Economics Department \\ Carleton University \\ James Yetman \\ School of Economics and Finance \\ University of Hong Kong
}

November 2001

first version March 2000 


\begin{abstract}
We develop a new way to test hypotheses about policymakers' targets, and implement that test for Canadian monetary policy. For example, if the Bank of Canada is targeting a 2 percent inflation rate, and if the Bank's instrument takes 8 quarters to affect inflation, then deviations of inflation from 2 percent should be uncorrelated with the Bank's information set lagged 8 quarters. We show there was a major change in the Bank's objectives near the time when formal inflation targets were announced, and that the Bank has indeed been targeting inflation since then.
\end{abstract}

Keywords: monetary policy, central banking, inflation targeting

JEL codes: E52, E61 


\section{Introduction}

In February 1991, the Bank of Canada announced a new policy of inflation targeting. In this paper, we test whether this announcement reflected a change in the actual behaviour of the Bank of Canada, and whether the Bank has indeed been targeting inflation since the announcement.

The objectives of a policy authority are not generally fully known: even if they are clearly stated, tactical considerations may lead to a divergence between stated and actual objectives. ${ }^{1}$ The objective of a policy authority can be thought of as the targeting of a particular macroeconomic variable (hereafter called the target variable) towards some level. For example, a central bank may attempt to target output to equal potential output, or alternatively target a constant inflation rate.

The standard approach to testing hypotheses about a central bank's objectives is to estimate a policy reaction function. There is a growing literature ${ }^{2}$ where economists try to estimate these reaction functions, usually as variants on a Taylor rule, for various monetary authorities around the world. The dependent variable of the estimated equation is the bank's policy instrument, while the independent variables include possible target variables and indicators of those target variables. A variant to the standard approach attempts to identify the policymaker's underlying preferences. $^{3}$

In this paper, we develop a new way to test hypotheses about what variable a policy authority is targeting, and we apply our test to the Bank of Canada. Our test turns the standard approach on its head. The standard approach can be thought of 
as looking for where the monetary authority's gun is pointing; our approach looks for where the bullets are hitting. According to this analogy, if we have correctly identified the monetary authority's target, then deviations of the bullets from the target should be random errors that are uncorrelated with any information available to the monetary authority when it pulled the trigger.

Hall (1978) proposed a way to test Friedman's Permanent Income Hypothesis: if individuals with rational expectations seek to smooth consumption over time, then changes in consumption between periods $t$ and $t+1$ should be uncorrelated with anything in the individual's information set at time $t$. Our test is similar in spirit to Hall's test. We show that if a policymaker is using an instrument to target a variable and there is a $j$ period lag in the effect of the instrument on the target variable, then deviations of the target variable from the target at time $t+j$ should be uncorrelated with anything in the policymaker's information set at time $t$, including inter alia the instrument itself. In practice, one major difference between our test and Hall's is that we use a lagged information set, to reflect the lag with which the policy instrument affects the target variable, whereas Hall uses a contemporaneous information set, to reflect the assumption that consumption is chosen contemporaneously. Econometrically, this means that the residuals in Hall's test should be serially uncorrelated, while the residuals in our test will be serially correlated, because our policymaker's required forecasting horizon is longer than our sampling frequency.

Kuttner and Posen (1999) come closest to the test proposed here. Starting 
from the standard Barro-Gordon model of central bank behaviour, they derive and estimate both a reaction function and an inflation forecasting equation. Indeed, they recognise in passing that under strict inflation targeting, deviations of inflation from target should be unforecastable, which is analogous to our test that deviations should be uncorrelated with the monetary authority's information set. But their inflation forecasting equation differs from our implicit forecasting equation in two important ways. First, they use only a one quarter lag in their forecasting equation (and indeed their model assumes, quite unrealistically, that the central bank can choose inflation contemporaneously), while we allow a six or eight quarter lag to take into account the conventional view that it takes six or eight quarters for changes in the central bank's instrument to have its maximum impact on the rate of inflation. Second, while Kuttner and Posen use only lagged inflation and unemployment in their inflation forecasting equation, our own method is based on the premise that no variable in the central bank's information set should provide any information on deviations of inflation from target. We therefore use a larger set of variables in our test. As a result of these differences between the two approaches, our results also differ significantly from those of Kuttner and Posen. We discover significant differences in the objectives of the Bank of Canada between the pre- and postinflation targeting periods, while they find none.

As an aside, we also note here that our result casts doubt on the validity of existing empirical causality tests. Suppose, for example, that monetary policy is chosen to target output to follow a smooth path over time and that monetary policy 
does indeed affect output with a (say) six quarter lag. If that policy is successful, output fluctuations will be uncorrelated with a six-quarter lagged information set, and econometric money-output causality tests will reject the hypothesis that money causes output. What others have interpreted as evidence against money-output causality could therefore also be interpreted as evidence of successful output targeting. The same applies to money-inflation causality tests if monetary policy is chosen to target inflation. ${ }^{4}$

We describe the statistical framework in Section 2, the method for empirical testing in Section 3, results in Section 4, and conclusions in Section 5.

\section{Statistical Framework}

Suppose that a policymaker is trying to target $X$ using the policy instrument $Z$, where $X$ is a scalar and $Z$ is a vector. Suppose further that the policy instrument acts on $X$ with a lag of $j$ periods, so that in terms of the underlying reduced form,

$$
X_{t+j}=F\left(Z_{t}, \ldots\right)
$$

The target variable $X_{t+j}$ may be decomposed into its rational expectation conditional on all information available to the policymaker at time $t$ plus some error term,

$$
X_{t+j}=E\left(X_{t+j} \mid I_{t}\right)+e_{t+j}
$$

Note that by definition of rational expectations, the random error term $e_{t+j}$ must be uncorrelated with everything in the policymaker's information set, $I_{t}$. And 
assuming that the policymaker knows the value of its own instrument at time $t$, the instrument $Z_{t}$ will be included in the information set $I_{t}$.

Suppose for example that the objective of the policymaker is to target $X$ such that it follows a time trend. That is, for some $B$, representing the desired rate of growth of the target variable,

$$
X_{t}^{*}=B t
$$

Given the lag between changes in the instrument and its effect on the target, plus the policymaker's imperfect information, exact targeting is impossible to achieve. Instead, the best the policymaker can do is to make the rational expectation of the target variable follow a time trend at and beyond the control lag $(j)$. The policymaker therefore sets the instrument $Z_{t}$ such that

$$
E\left(X_{t+j} \mid I_{t}\right)=B(t+j)
$$

Assuming that the probability distribution of $X_{t+j}$ around its expectation is symmetric and that the loss function of the policy authority is quadratic, this policy rule will minimize the variance of $X_{t+j}$ around its trend and hence minimize the expected loss. Substituting equation (4) into the decomposition identity given by equation (2) yields

$$
X_{t+j}=B(t+j)+e_{t+j}
$$

This equation is empirically testable; if equation (5) holds, deviations of $X$ about its trend should be uncorrelated with any variable in the policymaker's information set at time $t$, including inter alia all current and lagged values of the instrument, $\left\{Z_{t}, Z_{t-1}, \ldots\right\}$ 
To illustrate the intuition behind our approach, suppose the structure of the economy can be represented by

$$
X_{t+j}=B Z_{t}+G U_{t}+e_{t+j}
$$

where $B, G$, are fixed parameters and known to the policymaker, $X_{t}$ is inflation, $Z_{t}$ is the policy instrument, $U_{t}$ is some other variable that affects inflation and is observed by the monetary authority, and $e_{t}$ is an unforecastable, mean zero, error term.

If the bank targets a constant inflation rate of $C$, it will choose its instrument according to the policy reaction function

$$
Z_{t}=\frac{C-G U_{t}}{B}
$$

Substituting the reaction function into equation (6), we get

$$
X_{t+j}=C+e_{t+j}
$$

The inflation rate will equal a constant, plus an error term. Implementing our test of the hypothesis that the bank is targeting a constant rate of inflation, we would expect to discover that neither the policy instrument, $Z_{t}$, the exogenous indicator, $U_{t}$, nor both variables together, are correlated with deviations of inflation from the target, since neither will be correlated with the error term $e_{t+j}$. Furthermore, the high (or indeed perfect) multicollinearity between the independent variables $\left(U_{t}\right.$ and $Z_{t}$ ) will make it difficult (impossible) to identify the coefficients $B$ and $G$ in structural equation (6), thereby invalidating empirical causality tests. Empirical causality will be rejected even when, by assumption, it exists. 
We directly test equation (8) using tests of overidentifying restrictions, as in Hansen (1982). Even if the independent variables (those in the policymaker's information set) are highly collinear, our inference should not be affected. Whether the econometrician uses all of the information available to the monetary authority or only a subset of that information, if the bank targets a constant inflation rate, the implied overidentification restrictions should not be rejected. More generally, equation (5) can be replaced by any time path for the target variable desired by the policymaker, $X_{t}^{*}$, and the corresponding errors tested.

In testing equation (5) or (8), we are testing a joint hypothesis of (i) the policymaker's desired time path for the target variable, (ii) rational expectations on the part of the policymaker, (iii) correct knowledge by the policymaker of the structure of the economy, and (iv) the lag length with which the policy instrument is assumed to affect the target variable.

Clearly, the desired time path for the target variable must be feasible. For example, if the policymaker tried to use monetary policy to make real output grow permanently faster than potential output growth, we should not expect equation (5) to hold. But then a policymaker with rational expectations and correct knowledge of the structure of the economy would not try to achieve an unattainable target.

Our method of testing for targeting is very general, and requires no assumption about any particular underlying model of the economy. There are many different combinations of policymakers, policy instruments, and target variables for which the test could be implemented. We illustrate how our test can be applied by focusing 
on one example, the Bank of Canada.

\section{Empirical Testing}

We now test various hypotheses about what the Bank of Canada was seeking to target over the past 30 years. Since our method assumes that the target is a single scalar variable, we compare a number of mutually exclusive hypotheses about what that target was, for any given period of time. For example, we can test whether the Bank was targeting solely inflation, and we can test whether the Bank was targeting solely output, but we cannot test whether the Bank was targeting both inflation and output over the same period.

The time period we consider coincides with the longest available data panel: from the second quarter of 1968 to the first quarter of 2001. We use this quarterly data to test the overidentifying restrictions implied by a variety of possible hypothesised targets on a small number of key macroeconomic variables that economic theory suggests should be important in explaining future movements in the target variables. In principle, our method allows any variable whatsoever (provided it is in the Bank's information set) to be considered as a potential forecaster of deviations from a hypothesised target. But in practice, degrees of freedom constrain us to consider only those variables that one might expect to be useful a priori.

To test for inflation targeting, the dependent variable is the deviation of the growth rate of the core consumer price index (GCPIX) from its target. GCPIX is the measure of inflation that the Bank of Canada uses as a near-term operational target, and is constructed using overall CPI excluding food, energy, and indirect 
taxes. The variables included in the Bank of Canada's information set are: lags in GCPIX; lags in the growth rate of real gross domestic product (GRGDP); lags in the growth rate of narrow money (GM1); and lags in the interest rate on 90 Day Commercial Paper (CP). Because of the limited degrees of freedom available, we include 4 lags on each of the variables in the Bank's information set. CP is used because it is an interest rate on which monetary policy has an immediate and predictable impact. The mechanism by which monetary policy is implemented has changed over the last 30 years, making the Bank Rate and Overnight Rate less suitable. Other variables also considered were the percent change in the nominal exchange rate with the United States (E) and alternative measures of the interest rate, including measures of the term structure. The results reported in Section 4 are robust to these choices.

To test for output growth targeting, the dependent variable is deviations of GRGDP from its target. The variables included in the Bank of Canada's information set are: lags in CP (and alternative measures of interest rates); lags in the percent change in the real exchange rate with the United States (RE); and lags in GRGDP itself.

We use two different sampling approaches to test hypotheses about possible targets of the Bank of Canada. Our first approach uses tests of overidentifying restrictions over (2-sided) rolling samples, adding and dropping one observation each time. Each rolling sample consists of 36 consecutive quarters of data. Our second approach uses tests over the full sample, but allowing for endogenous break-points 
in the target using Andrews (1993), and incorporating robust variance-covariance estimation using Newey and West (1987).

The advantage of our first approach (rolling samples) is that it allows for changes in the economic structure or the policymaker's target to evolve continuously over time, whereas the second approach (full sample with structural breaks) allows only for discrete breaks in the economic structure or policymaker's target. (Strictly speaking, we should also have used the original data as it became available, rather than final revised data, but doing so was impractical). We also use 1-sided rolling samples as warranted, to determine whether it is the addition of new data or the loss of old data that drives changes in the test statistic over the sample. This practice enables us to comment on changes in the Bank of Canada's target at particular points in time during our sample. But there is also a disadvantage to using a rolling sample, because Hansen's test of overidentifying restrictions is a large sample test, and our rolling samples are necessarily smaller than the full sample. The degree of consistency between the results obtained by our two approaches (rolling samples and full sample) will provide an indication of the size of distortion present in the tests based on rolling samples.

Suppose we wish to test whether the Bank of Canada targets core inflation to equal 2 percent. We would then construct the variable representing deviations from target as

$$
u_{t}=\operatorname{GCPIX}_{t}-2
$$


and compute Hansen's test statistic $u^{\prime} Z W Z^{\prime} u$, where

$$
\begin{gathered}
Z_{t}=\left\{\mathrm{GRGDP}_{t-j}, \ldots, \mathrm{GRGDP}_{t-j-k}, \mathrm{CP}_{t-j}, \ldots, \mathrm{CP}_{t-j-k}, \mathrm{GM}_{t-j}, \ldots, \mathrm{GM}_{t-j-k},\right. \\
\left.\operatorname{GCPIX}_{t-j}, \ldots, \mathrm{GCPIX}_{t-j-k}\right\},
\end{gathered}
$$

$j$ is the number of lags at which the policy instrument has an impact on GCPIX, $k$ is the number of lags on all of the explanatory variables that will be included in the Bank's information set, and $W$ is a weighting matrix. In the case of rolling samples, we use $W=\left(Z^{\prime} Z\right)^{-1}$ due to degrees of freedom constraints, but when we estimate on the full sample, we use instead the Newey-West variance-covariance estimator that is robust to heteroskedasticity and autocorrelation, allowing for $\mathrm{MA}(1)$ errors. Strictly, the errors are likely to be distributed as an $\mathrm{MA}(j-1)$; however degrees of freedom limit our ability to fully model these.

Hansen's test statistic is distributed asymptotically as $\chi_{4 k}^{2}$ under the null hypothesis that $u$ and $Z$ are uncorrelated, where $4 k$ is the number of overidentifying restrictions in this case. This test can be completed for each rolling sample, with a plot of the test statistics over time indicating movements by the Bank of Canada towards or away from this hypothesised target.

When we test over the full sample, we will allow for up to 2 endogenous breakpoints using the Sup-W test of Andrews (1993). This is computed as

$$
\operatorname{SupW}=\max _{\pi} T\left[\frac{u^{\prime} u-u_{1}^{\prime} u_{1}-u_{2}{ }^{\prime} u_{2}}{u_{1}^{\prime} u_{1}+u_{2}^{\prime} u_{2}}\right]
$$

where $u$ is a $T \times 1$ vector of deviations from the target over the full sample, $u_{1}$ is a 
$T^{*} \times 1$ vector from the first sub-sample, $u_{2}$ is a $\left(T-T^{*}\right) \times 1$ vector from the second sub-sample, $\pi=T^{*} / T$, and $\pi \in[0.15,0.85]$.

We also compare the estimated break dates with the dates of announcements by the Bank of Canada using confidence intervals as in Bai (1997). Given estimated inflation targets for two adjacent sub-samples of $\hat{X}_{1}$ and $\hat{X}_{2}$, a confidence interval can be constructed as

$$
\left(\hat{T}^{*}-c / \hat{\Lambda}-1, \hat{T}^{*}+c / \hat{\Lambda}+1\right)
$$

where

$$
\hat{\Lambda}=\frac{\left(\hat{X}_{1}-\hat{X}_{2}\right)^{2}}{\frac{1}{T}\left[\sum_{t=1}^{T} \epsilon_{t}^{2}+\sum_{l=1}^{L} \sum_{t=l+1}^{T} \frac{2 l}{L+1} \epsilon_{t} \epsilon_{t-l}\left(D_{1, t} D_{1, t-l}+D_{2, t} D_{2, t-l}\right)\right]},
$$

and

$$
\epsilon_{t}=\operatorname{GCPIX}_{t}-\hat{X}_{1} D_{1, t}-\hat{X}_{2} D_{2, t}
$$

where $D_{1, t}$ and $D_{2, t}$ are dummy variables that correspond with each of the subsamples, $\hat{T}^{*}$ is the estimated break date, and $c=11$ is consistent with a $95 \%$ confidence interval. A confidence interval constructed in this fashion incorporates the Newey-West (1987) variance-covariance estimator to accommodate autocorrelation and heteroskedasticity.

One remaining issue is how to choose $j$, the length of time required for the working of the monetary transmission mechanism. There is probably no single lag length at which monetary policy impacts the economy, but a complete distribution of lags. The Bank would wish to operate with the smallest feasible lag length for the control of the economy, since the longer it waits, the more information it has 
available when it sets its instrument. But there is a danger that operating on too short a lag length may cause "instrument instability". Consider a simple example, where monetary policy affects inflation at two lag lengths, but where it is twice as powerful at the longer lag length. If the Bank operates only on the shorter lag length, the required oscillations in the interest rate in response to a one-time shock would double every period. Unfortunately, a full examination of what determines the shortest feasible lag length (and not subject to instrument instability) is beyond the scope of this paper.

Our results will depend on our choice of $j$ : if we choose a $j$ that is too large, our test will be biased towards not rejecting the null hypothesis. If $j$ is too small, our test will be biased towards rejecting the null hypothesis. We consider values of $j$ equal to 6 and 8 quarters, consistent with the predominant view within the Bank of Canada, and we also describe the extent to which our results are sensitive to the choice of lag length.

\section{Results}

We will now discuss the results for a number of hypothesised policy targets for core inflation and real output, first on rolling samples and then over the full sample. We will outline the estimation and results for each in turn.

\subsection{Inflation Targeting}

Inflation targeting is consistent with the stated policy objectives of the Bank of Canada over the past 10 years. In January 1988, the Bank's Governor John Crow (1988) made it clear in the Hansen Lecture that the longer-run objective of monetary 
policy should be price stability. In February 1991, this was formalised when the Federal Government and the Bank of Canada jointly announced explicit inflation targets for reducing the rate of inflation towards 2 percent, with a target range of \pm 1 percent. Figure 1 contains the official inflation targets and realised inflation; vertical bars indicate the timing of the Hansen Lecture and the announcement of targets.

Although the official announcement committed the Bank to a target range for inflation, our test focuses on particular point targets, with special interest in the mid-point of that target range. We do this partly for simplicity, because testing hypotheses about a target range would involve some complicated non-linear econometrics. But we also think our approach may be realistic, because if the Bank has imperfect control over inflation, then the best way for the Bank to keep inflation from wandering outside that range my be to target some inflation rate point strictly inside the allowed range. If the Bank's loss function is symmetric, the best point to target would be the mid-point. On the other hand, if the Bank was more concerned about inflation rising above the target range than falling below it, the Bank may well target an inflation rate below the mid-point of the range.

First we consider a test of the announced target since targets first came into effect in the fourth quarter of 1992; the results are contained in the first row of Table 1. The test statistic for overidentifying restrictions (19.15) cannot be rejected at usual significance levels. Therefore the announced target for monetary policy cannot be rejected empirically. 
As an alternative, consider a target of core inflation equal to 2 percent, which is consistent with the Bank of Canada's stated target since the end of 1995. Figure $2 \mathrm{~A}$ contains test statistics for the hypothesis of inflation targeting as outlined in the previous section. These are asymptotically $\chi^{2}$-distributed tests of the hypothesis that none of the variables included in the Bank of Canada's information set explain deviations of GCPIX from the target. The horizontal dotted lines represent the nominal critical values at the 5 percent and 1 percent levels respectively, and the dates on the horizontal axis are the first quarterly observation included in the rolling sample; the final observation is 36 quarters, or 9 years, later.

Rolling samples that include more quarters since explicit inflation targets were announced by the Bank have higher $p$-values, and therefore indicate less evidence against the null hypothesis. When all recent data are included, an inflation target of 2 percent cannot be rejected at the 1 percent level of significance- even though some of the observations included in the regression predate an explicit inflation target of $2 \%$. Figure $2 \mathrm{~B}$ demonstrates that very similar results can be obtained assuming a transmission mechanism lag length of 6 quarters $(j=6)$.

To illustrate that our test is sufficiently powerful to discriminate between alternative targeting hypotheses, Figure $2 \mathrm{C}$ contains the test statistics for a null hypothesis of an inflation target of 4 percent, for $j=8$. While this null hypothesis cannot be rejected for a small number of samples starting in the early 1980s, it is rejected when most of the quarters in the regression are from the explicit inflationtargeting period. Similarly, an inflation target of 1 percent (not shown) can be 
rejected for all periods.

As an alternative objective, consider the hypothesis that the Bank of Canada targets core inflation to equal its recent past values, defined here as a 20-quarter moving average so that temporary deviations in inflation have only a small impact on the target. Figure 3A contains the test statistics. Around the middle of the sample period, the test statistics decline substantially, suggesting that this hypothesis becomes more plausible around this time, although there is evidence that the monetary authority was not targeting core inflation to its recent past (as defined here) over the entire sample. This change (starting in the first quarter of 1982 in Figure 3A) may be due to the loss of old data from the rolling sample, or it may be due to the addition of new data. To determine which of these is responsible, the estimation is repeated twice, in one-sided rolling samples. First, the sample size used for estimation starts with the full sample and becomes progressively smaller as the earliest observation is dropped with each estimation, until only 36 observations remain (labeled "Dropping Data"). Second, the sample begins with the first 36 observations and becomes progressively larger as one observation is added with each estimation, until the full sample is included (labeled "Adding Data").

Figure 3B contains the test statistics. In the case of adding data, the horizontal axis represents the date of the final observation included in the sample less 36 quarters. In the case of dropping data, the horizontal axis represents the earliest observation included in the sample. The test statistics from the two-sided rolling samples are also included as a point of reference. The large change in the test 
statistic in Figure 3A coincides with that obtained by dropping one observation each quarter, and is therefore driven not by data from the early 1990s, when inflation targets were announced, but by data from the early 1980s. In contrast, the test statistic from adding one additional observation each regression remains high throughout the sample period. Our results are therefore consistent with an accommodative monetary policy until the early 1980s, followed by an anti-inflationary policy thereafter. ${ }^{5}$

We now consider estimation over the full sample, results from which are contained in Table 1. First note that an inflation target of $2 \%$ over the full sample can be rejected at the $5 \%$ level, implying that information available to the monetary authority when policy was set is correlated with inflation deviations from $2 \%$. We next allow for an endogenously estimated inflation target. Our estimate of the endogenous target is equal to the estimated constant using G.M.M. estimation, allowing for robust variance-covariance computation and M.A.(1) errors using Newey and West (1987).

Over the full sample, the best estimate of the inflation target is $4.42 \%$, but this estimate can nevertheless be rejected as an inflation target at the $1 \%$ level. Next we provide for an endogenous-break point, allowing for a change in the target, using the Sup-W test of Andrews (1993). This procedure yields a break at the end of 1983 that is statistically significant at the $1 \%$ level. Now estimating a target separately over each of the two sub-samples, we get an estimated inflation target of $8.12 \%$ for the first period, which cannot be rejected, and an estimated inflation target of 
$2.61 \%$ for the second period, which can be rejected at the $10 \%$ level. However, there is a second statistically significant break-point occurring at the end of the first quarter of 1991. Now estimating over the three sub-samples separately, we have inflation targets of $8.12 \%, 4.11 \%$, and $1.61 \%$ respectively, and none of these can be rejected using tests of over-identifying restrictions. These therefore provide valid point estimates of the inflation targets of monetary policy over each of the respective periods.

In the above results we specified an inflation target defined over a single quarter. The remainder of Table 1 considers an inflation target specified as a four-quarter moving average, followed by an eight-quarter moving average. These are consistent with a monetary authority that desires stable inflation over a 1-year or 2-year horizon respectively. Qualitatively the results obtained here are very similar to those obtained above; in all cases, three distinct periods with different inflation targets are identified, with a successively lower target inflation rate estimated in each subsequent period, that cannot be rejected using tests of over-identifying restrictions. One slight difference is the point at which the latest, low inflation period is identified to commence, varying from the second quarter of 1991 in the case of the quarterly rate of inflation to the fourth quarter of 1991 in the case of an 8 quarter moving average.

Constructing a 95\% confidence interval around the estimated break-point date, this spans $1.7,1.7$, and 1.8 quarters each side of the point estimate for 1-quarter, 1-year, and 2-year horizon target respectively, assuming no serial correlation $(L=0$ 
in equation (13)). These reduce slightly to $1.5,1.6$, and 1.5 respectively, allowing for 7-quarters of serial correlation. Thus with the exception of the 2-year horizon, a 95\% confidence interval contains the announcement of explicit inflation targets by the Bank of Canada (February 1991).

Note here that the results obtained by our two approaches (rolling samples vs full sample) are consistent, indicating that any size distortion introduced by the small sample with the rolling sample approach is small.

\subsection{Targeting Real GDP}

We now consider hypotheses about possible monetary policy targets specified in terms of real GDP. Consider first the hypothesis that the Bank of Canada has an objective that the economy continues to grow at recent historical levels, here represented with a 20 -quarter moving average. Figure 4 contains the test statistics for the rolling sample approach, and shows that for all periods, this hypothesis can be rejected. A second hypothesis, that the Bank of Canada targets potential output, defined using the internal measure of the Bank of Canada, in real time, was also rejected using the rolling sample approach. ${ }^{6}$ However, neither of these two hypothesised targets was ever rejected in the context of full-sample estimation, with or without endogenous break-points. Further investigation revealed that the inconsistency between the results from the two approaches (rolling sample versus full sample) stems from differences in the size of the estimated variance-covariance matrix. Indeed, utilizing the Newey-West robust variance-covariance matrix results in insignificant overidentifying test statistics in Figure 4 for all rolling samples. We 
interpret these results as evidence of some degree of output targeting by the Bank of Canada over the full sample period.

\section{Conclusions}

We have developed and implemented a method to test hypotheses about what it is a policy authority is targeting. Our method focuses on the idea that the deviations between the actual outcomes and the intended target of a rational policy authority should be uncorrelated with the policy authority's information set when it sets its instrument. We have also shown in passing that commonly used empirical causality tests are of dubious value in detecting causal relationships between policy instruments and policy targets.

In February 1991, the Federal Government and the Bank of Canada jointly announced a sequence of explicit targets for inflation. We have shown that the date of the announcement approximately coincided with an actual change in monetary policy. We can reject the hypothesis that the Bank was targeting low inflation before 1991, but we cannot reject the hypothesis that it was targeting its announced inflation targets thereafter. By our test, the policy announcement reflected a change in actual policy. The Bank has done exactly what it said it would do.

Some caveats are of course in order. We have jointly tested rational expectations on the part of the policymaker, and our hypothesis about the lag length in the transmission mechanism with which the instrument influences the target variable, along with our main hypothesis about the policymaker's target. If either of the first two assumptions is incorrect, our test will be biased. Also, monetary author- 
ities may well have multiple objectives in practice, whereas our test requires that the target be a scalar variable. For a policymaker with fixed weights on multiple objectives, and facing a fixed trade-off between them, it may be possible to convert multiple objectives into a single scalar target, in which case our test can be implemented as it stands. But otherwise, the extension of our test to consider the case of multiple competing objectives must be left for future research. 


\section{References}

Andrews, Donald W. K. (1993) "Tests for Parameter Instability and Structural Change with Unknown Change Point," Econometrica 61(4), 821-56

Bai, Jushan (1997) "Estimation of a Change Point in Multiple Regression Models," Review of Economics and Statistics 79(4), 551-63

Bernanke, Ben S. and Ilian Mihov (1997) "What does the Bundesbank Target?" European Economic Review 41(6), 1025-53

Bernanke, Ben S. and Ilian Mihov (1998) "Measuring Monetary Policy," Quarterly Journal of Economics 113(3), 869-902

Buiter, Willem H. (1984) "Granger-Causality and Policy Effectiveness," Economica $51(202), 151-62$

Butler, Leo (1996) “The Bank of Canada's New Quarterly Projection Model (QPM) Part 4: A Semi-Structural Method to Estimate Potential Output: Combining Economic Theory with a Time-Series Filter," Bank of Canada, Technical Report No. 77

Cecchetti, Stephen G., Margaret M. McConnell and Gabriel Perez Quiros (1999) “Policymakers' Revealed Preferences and the Output-Inflation Variability Trade-off: Implications for the European System of Central Banks," Federal Reserve Bank of New York

Cecchetti, Stephen G. and Michael Ehrmann (1999) "Does Inflation Targeting Increase Output Volatility? An International Comparison of Policymakers' Preferences and Outcomes," NBER Working Paper No. 7426

Clarida, Richard, Jordi Gali, and Mark Gertler (1998) "Monetary Policy Rules in 
Practice: Some International Evidence," European Economic Review 42(6), $1033-67$

Crow, John (1998) "The Work of Canadian Monetary Policy," Bank of Canada Review (February), 3-17

Favero, Carlo A. and Riccardo Rovelli (1999) "Modelling and Identifying Central Banks' Preferences," Centre for Economic Policy Research, Discussion Paper No. 2178

Hall, Robert E. (1978) "Stochastic Implications of the Life Cycle-Permanent Income Hypothesis: Theory and Evidence," Journal of Political Economy 86(6), 97187

Hansen, Lars P. (1982) "Large Sample Properties of Generalized Method of Moments Estimators," Econometrica 50(4), 1029-54

Kuttner, Kenneth N. and Adam S. Posen (1999) "Does Talk Matter After All? Inflation Targeting and Central Bank Behavior," Federal Reserve Bank of New York, Staff Report No. 88

Newey, Whitney K. and Kenneth D. West (1987) “A Simple, Positive Semi-Definite, Heteroskedasticity and Autocorrelation Consistent Covariance Matrix," Econometrica 55(3), 703-08

Swank, Otto H. and Job Swank (1993) "In Search of the Motives Behind U.S. Fiscal Macroeconomic Policy," Applied Economics 25(8), 1013-22

Thornton, Daniel L. (1999) "The Fed's Influence on the Federal Funds Rate: Is It Open Market or Open Mouth Operations?" Federal Reserve Bank of St. Louis, Working Paper No. 99-022A 


\section{Footnotes}

Lead footnote. Rowe: Economics Department, Carleton University, Ottawa, Ontario, Canada K1S 5B6, (613) 520-2600 ext. 3773, nick_rowe@carleton.ca; Yetman: School of Economics and Finance, University of Hong Kong, Pokfulam Road, Hong Kong, (852) 2857-8506, jyetman@econ.hku.hk. We thank seminar participants at the Bank of Canada and Carleton for their comments, and two anonymous referees for comments that substantially improved the paper. Frederick Beauregard-Tellier provided excellent research assistance. All remaining errors are the authors' responsibility.

1. For example, Thornton (1999) documents evidence from FOMC transcripts that the Federal Reserve started targeting the Federal Funds Rate in 1982, although their official stated target was Borrowed Reserves until 1989. He argues that this discrepancy was due to political considerations.

2. For example, see Clarida, Gali and Gertler (1998) or Bernanke and Mihov (1997).

3. For example, see Swank and Swank (1993), Bernanke and Mihov (1998), Favero and Rovelli (1999), Cecchetti, McConnell and Perez Quiros (1999), or Cechetti and Ehrmann (1999).

4. Buiter (1984) makes a similar point.

5. Because the horizontal axis represents the end of the sample less 36 quarters, test statistics after the first quarter of 1982 include information from the inflation targeting period.

6. This measure combines economic structure with a time-series filter, and is described in Butler (1996). The filter was run recursively, with the last data 
point at each recursion used to construct the series. Since only contemporaneous or lagged data are used at each recursion, it is effectively a one-sided filter, and in that sense may be thought of as a real-time measure of potential output. Note however that revised data are used, rather than the original data that were available to the monetary authority at the time to formulate monetary policy. 
Table 1. Full Sample Results.

\begin{tabular}{|c|c|c|c|c|}
\hline Sample & Coefficient (s.e.) & $\begin{array}{l}\text { O.I.R. Statistic } \\
\text { [ SupW statistic }\end{array}$ & $\begin{array}{l}\text { d.f. } \\
\pi\end{array}$ & $\begin{array}{l}\text { significance } \\
\left.\text { significance }^{\dagger}\right]\end{array}$ \\
\hline \multicolumn{5}{|c|}{ Stated Inflation Target } \\
\hline 1992:4 - 2001:1 & n.a. & 19.15 & 20 & 0.51 \\
\hline \multicolumn{5}{|c|}{ Inflation Target of $2 \%$} \\
\hline 1971:2 - 2001:1 & n.a. & 31.36 & 20 & 0.05 \\
\hline \multicolumn{5}{|c|}{ Endogenous Inflation Target } \\
\hline 1971:2 - 2001:1 & $4.42(0.29)$ & $\begin{array}{l}37.46 \\
{[204.31}\end{array}$ & $\begin{array}{l}19 \\
0.49\end{array}$ & $\begin{array}{l}0.01 \\
* * *\end{array}$ \\
\hline $\begin{array}{l}\text { 1971:2 - 1982:4 } \\
\text { 1983:1 - 2001:1 }\end{array}$ & $\begin{array}{l}8.12(0.17) \\
2.61(0.17)\end{array}$ & $\begin{array}{l}16.97 \\
27.73 \\
{[34.26}\end{array}$ & $\begin{array}{l}19 \\
19 \\
0.77\end{array}$ & $\begin{array}{l}0.59 \\
0.09 \\
* * *\end{array}$ \\
\hline 1971:2 - 1982:4 & $8.12(0.17)$ & 16.97 & 19 & 0.59 \\
\hline $1983: 1-1991: 1$ & $4.11(0.09)$ & 13.32 & 19 & 0.82 \\
\hline 1991:2 - 2001:1 & $1.61(0.09)$ & 14.73 & 19 & 0.74 \\
\hline \multicolumn{5}{|c|}{ Endogenous Inflation Target: M.A.(4) } \\
\hline 1971:2 - 2001:1 & $4.36(0.28)$ & $\begin{array}{l}35.62 \\
{[251.56}\end{array}$ & $\begin{array}{l}19 \\
0.51\end{array}$ & $\begin{array}{l}0.01 \\
* * *]\end{array}$ \\
\hline $\begin{array}{l}\text { 1971:2 - 1983:2 } \\
1983: 3-2001: 1\end{array}$ & $\begin{array}{l}7.93(0.19) \\
2.64(0.17)\end{array}$ & $\begin{array}{l}17.99 \\
28.69 \\
{[46.62}\end{array}$ & $\begin{array}{l}19 \\
19 \\
0.78\end{array}$ & $\left.\begin{array}{l}0.52 \\
0.07 \\
* * *\end{array}\right]$ \\
\hline 1971:2 - 1982:4 & $8.02(0.19)$ & 17.12 & 19 & 0.58 \\
\hline $1983: 1-1991: 2$ & $4.15(0.04)$ & 10.80 & 19 & 0.93 \\
\hline 1991:3 - 2001:1 & $1.62(0.02)$ & 16.42 & 19 & 0.63 \\
\hline \multicolumn{5}{|c|}{ Endogenous Inflation Target: M.A.(8) } \\
\hline 1971:2 - 2001:1 & $4.46(0.27)$ & $\begin{array}{l}35.34 \\
{[284.18}\end{array}$ & $\begin{array}{l}19 \\
0.51\end{array}$ & $\left.\begin{array}{l}0.01 \\
* * *\end{array}\right]$ \\
\hline $\begin{array}{l}1971: 2-1983: 2 \\
1983: 3-2001: 1\end{array}$ & $\begin{array}{l}7.96(0.18) \\
2.79(0.19)\end{array}$ & $\begin{array}{l}17.58 \\
29.48 \\
{[52.54}\end{array}$ & $\begin{array}{l}19 \\
19 \\
0.78\end{array}$ & $\begin{array}{l}0.55 \\
0.06 \\
* * *]\end{array}$ \\
\hline 1971:2 - 1983:1 & $7.96(0.17)$ & 17.55 & 19 & 0.55 \\
\hline $1983: 2-1991: 3$ & $4.10(0.05)$ & 14.32 & 19 & 0.76 \\
\hline 1991:4 - 2001:1 & $1.63(0.03)$ & 12.64 & 19 & 0.86 \\
\hline
\end{tabular}

$\dagger$ Significance levels from Andrews (1993), Table 1: $10 \%(*) ; 5 \%(* *) ; 1 \%(* * *)$ 

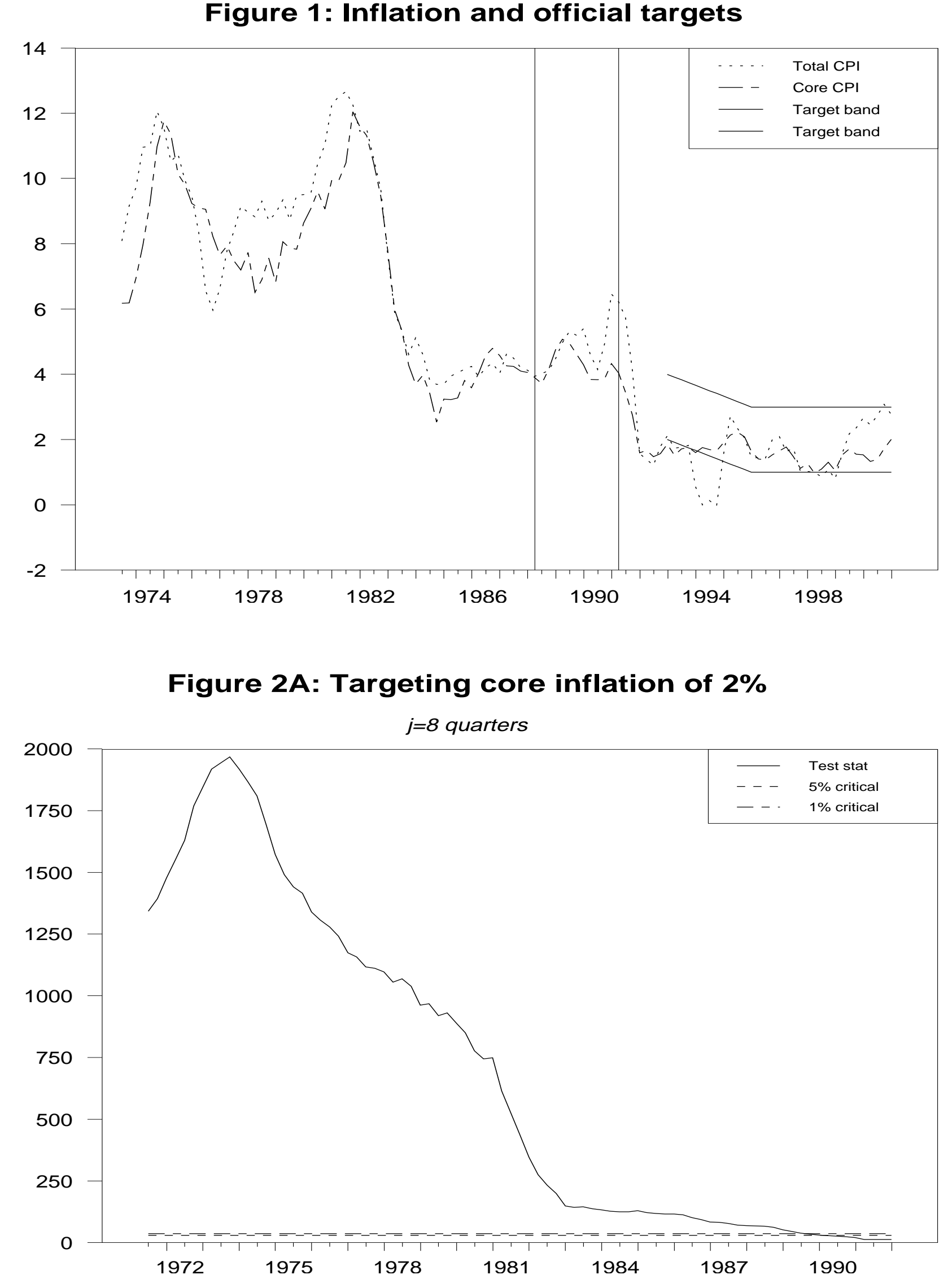
Figure 2B: Targeting core inflation of $2 \%$

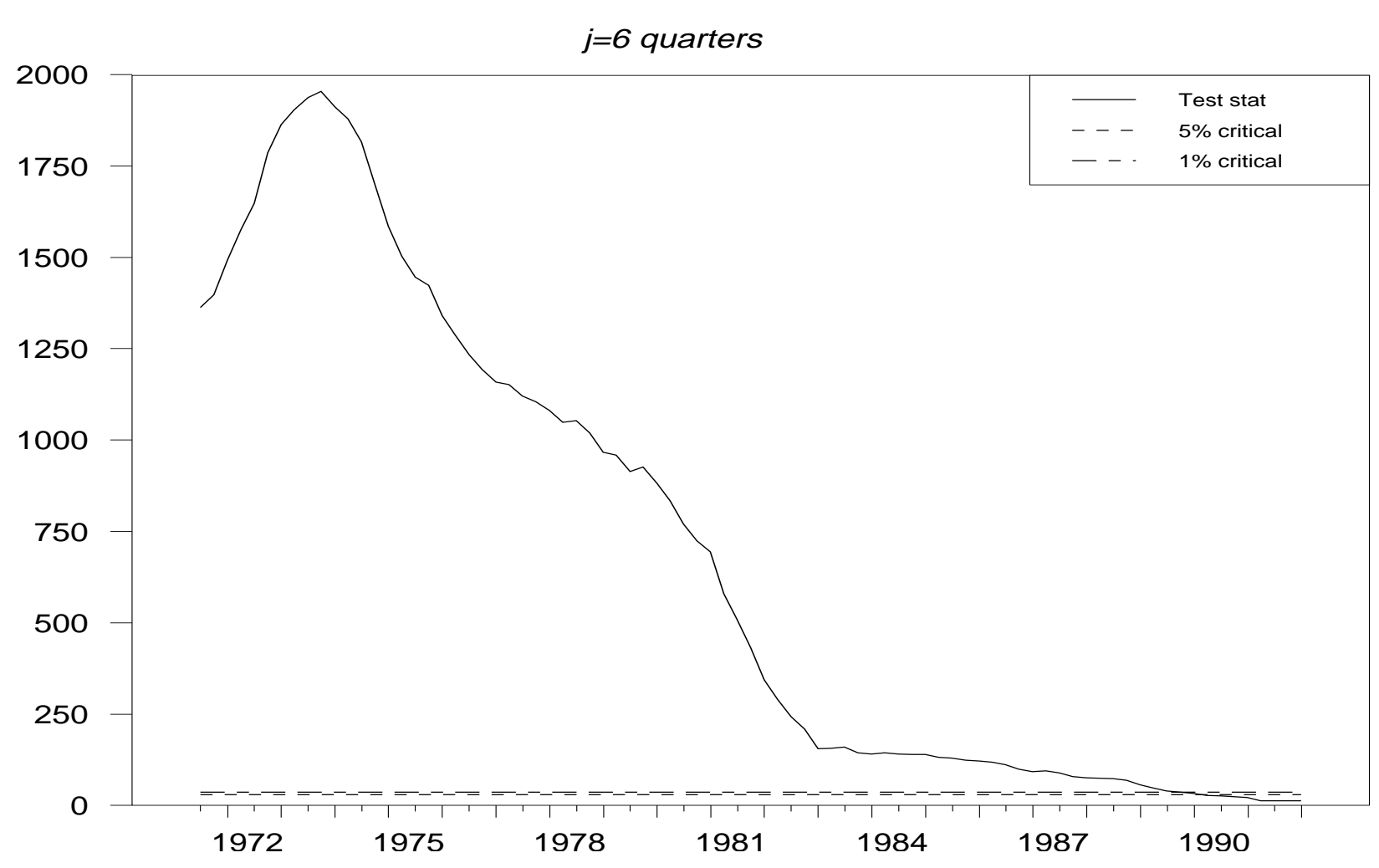

Figure 2C: Targeting core inflation of $4 \%$

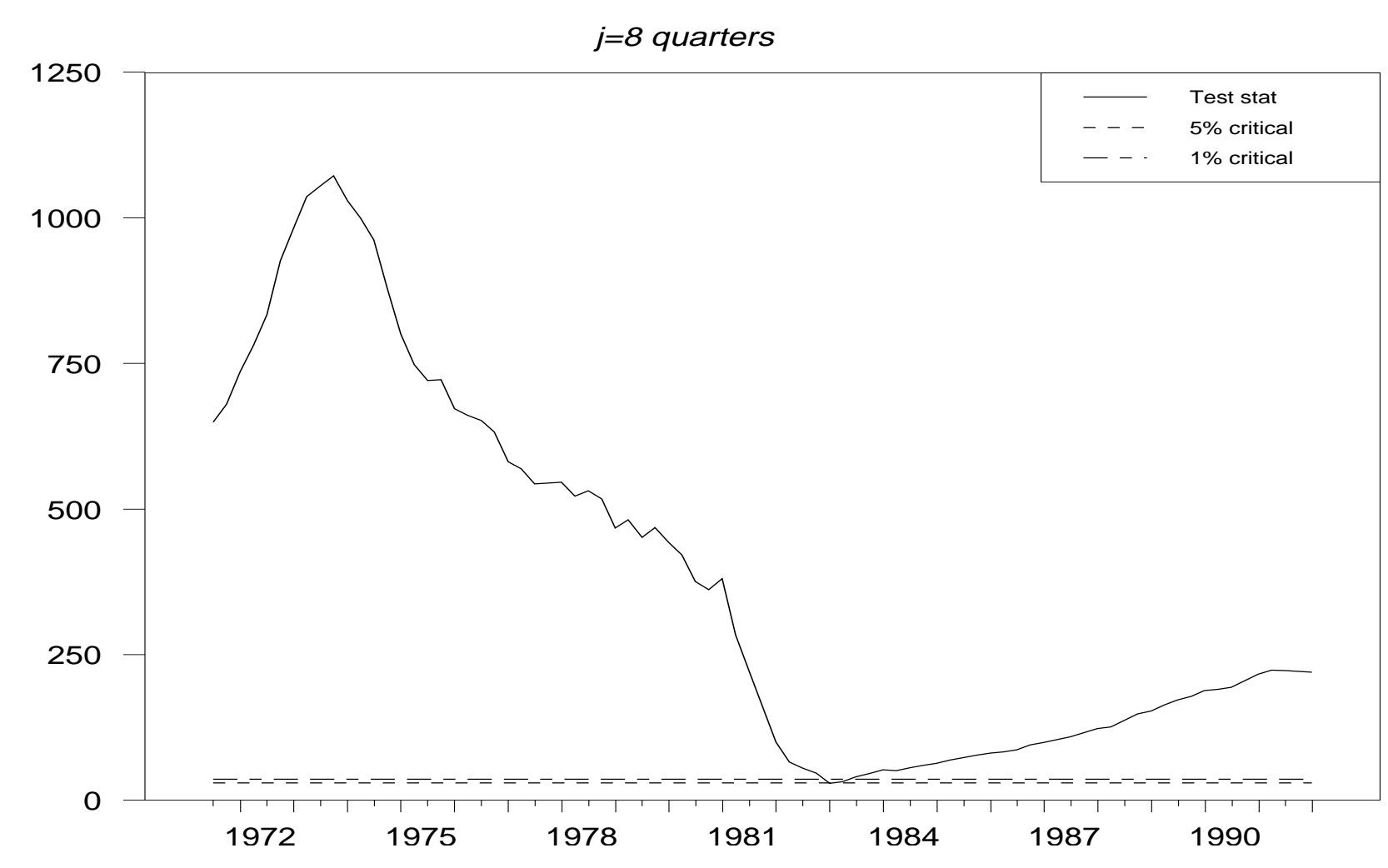


Figure 3A: Targeting core inflation equal to its recent past $j=8$ quarters

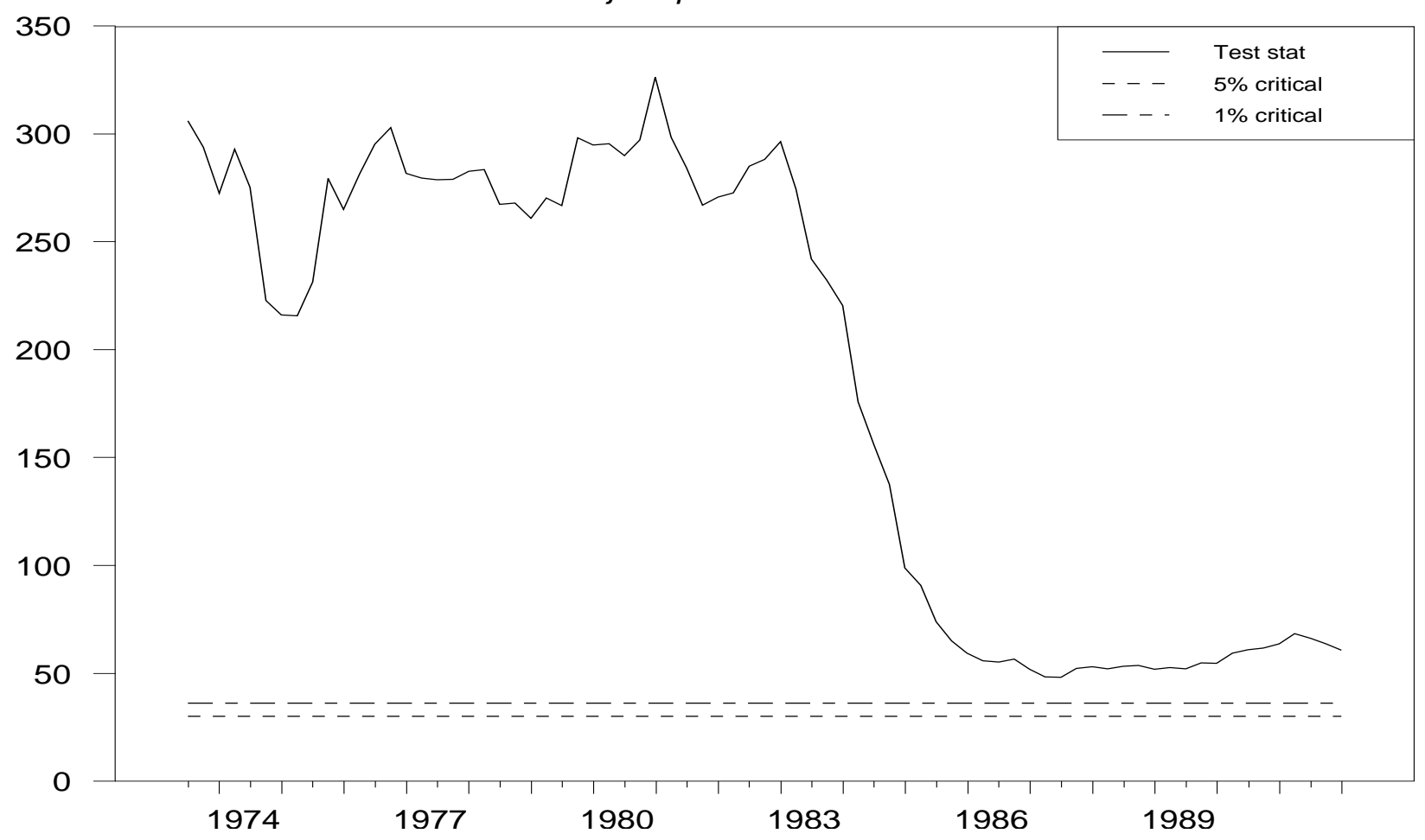

Figure 3B: Targeting core inflation equal to its recent past Rolling samples

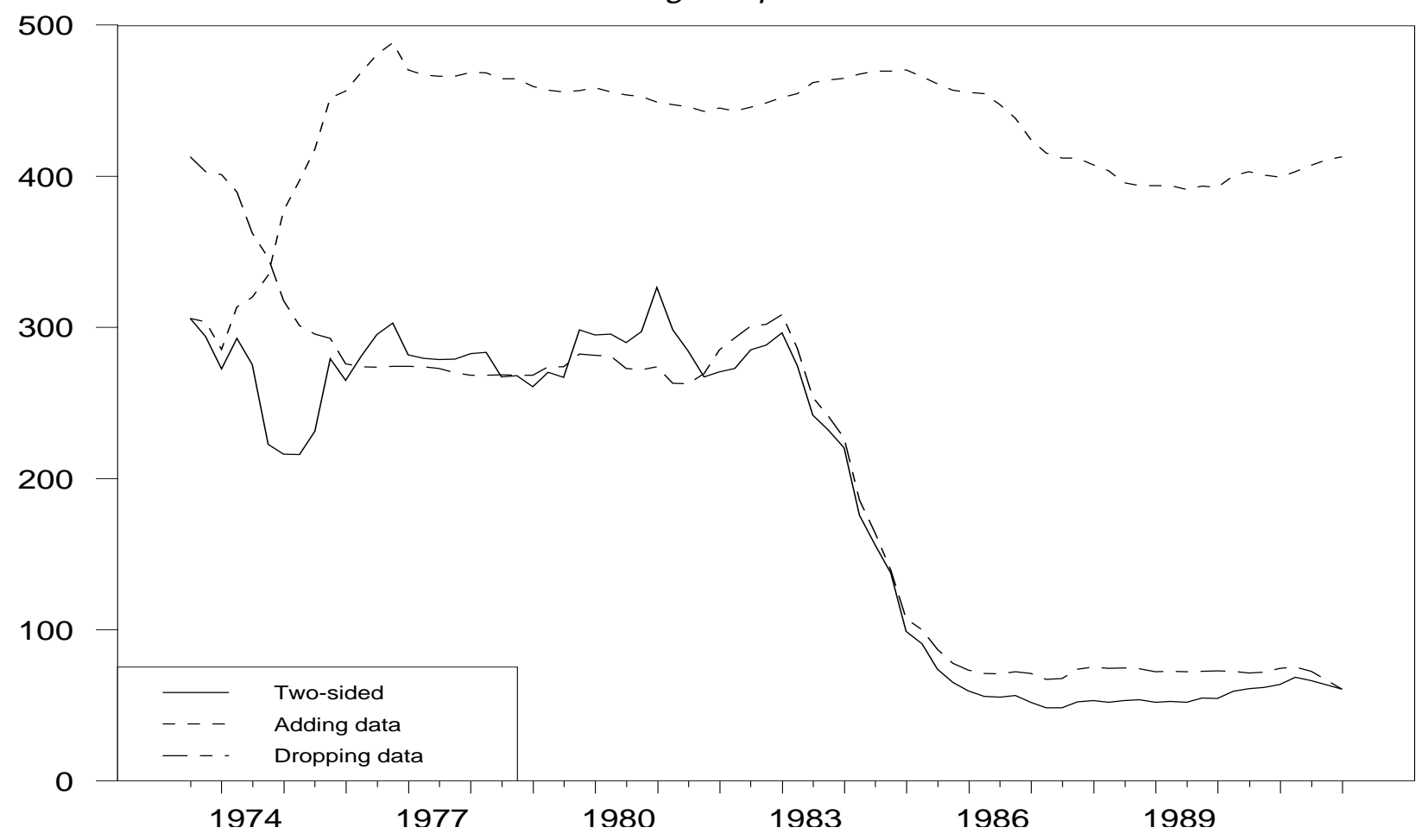


Figure 4: Targeting recent growth rates

$j=8$ quarters

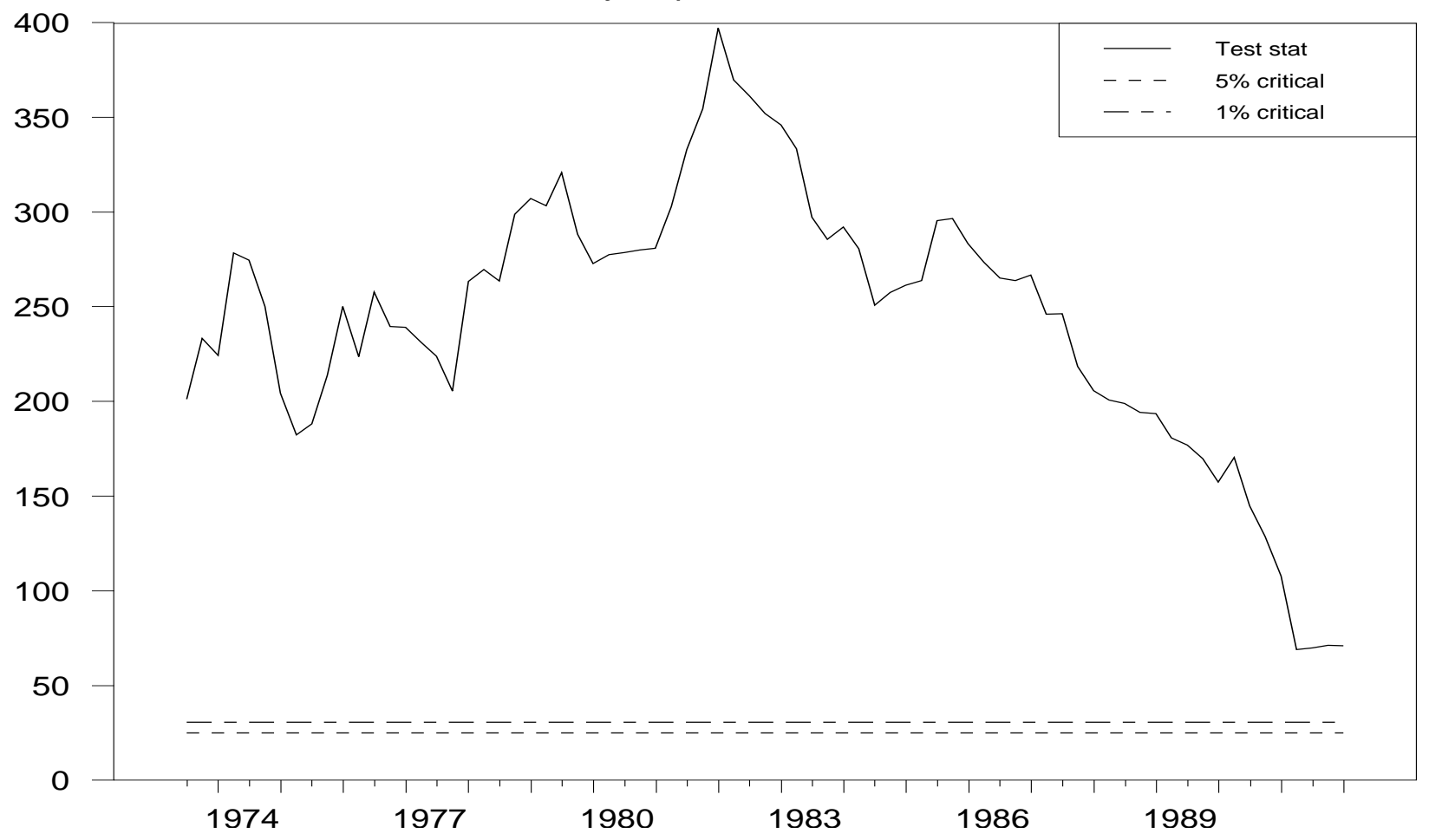

